\title{
Triterpene Profiling of Neem Exudate (Toddy) Using UHPLC-QTOF- MS and its Anti-inflammatory Activity
}

\section{(ㄷ) (i) $(8)$}

\author{
Authors \\ Ranendra Pratap Biswal', Durga Prasad Patnana', Sujith Kumar Pulukool2, Venketesh Sivaramakrishnan², \\ Ashish Pargaonkar ${ }^{3}$, Rajesh Babu Dandamudi ${ }^{1}$
}

\section{Affiliations}

1 Department of Chemistry, Sri Sathya Sai Institute of Higher Learning, Prasanthi Nilayam Campus, Puttaparthi, Andhra Pradesh, India

2 Department of Biosciences, Sri Sathya Sai Institute of Higher Learning, Prasanthi Nilayam Campus, Puttaparthi, Andhra Pradesh, India

3 Agilent Technologies India Pvt Ltd, Bengaluru, India

\section{Key words}

neem toddy, UHPLC-QTOF-MS, metabolites, principal component analysis, anti-inflammation, Neem (Azadirachta indica); family Meliaceae

\section{received $\quad 25.06 .2020$ \\ received $\quad 03.02 .202$ \\ accepted 22.02.2021}

\section{Bibliography}

Planta Med Int Open 2021; 8: e25-e33

DOI 10.1055/a-1397-8510

ISSN 2509-9264

(c) 2021. The Author(s).

This is an open access article published by Thieme under the terms of the Creative Commons Attribution-NonDerivative-NonCommercial-License, permitting copying and reproduction so long as the original work is given appropriate credit. Contents may not be used for commercial purposes, or adapted, remixed, transformed or built upon. (https://creativecommons. org/licenses/by-nc-nd/4.0/).

Georg Thieme Verlag KG, Rüdigerstraße 14,

70469 Stuttgart, Germany

\section{Correspondence}

Dr. Rajesh Babu Dandamudi Assistant Professor

Dept. of Chemistry, Sri Sathya Sai Institute of Higher Learning, Prasanthi Nilayam Campus

Puttaparthi

Andhra Pradesh

India

Tel.: + 91-9441587413

mailrajeshbabu@gmail.com $\circledast$ Supplementary Material is available under https://doi. org/10.1055/a-1397-8510

\section{ABSTRACT}

Neem tree (Azadirachta indica) is one of the richest sources of secondary metabolites. More than 250 natural products have been characterized from various parts of the neem tree. These include diterpenoids, triterpenoids, steroids, flavonoids, coumarins, hydrocarbons, and fatty acids. Many of these products possess therapeutic properties. Neem exudate or toddy is a milky white liquid with a strong smell secreted from the angle between the 2 main branches of old trees. Profiling of neem toddy for the presence of active metabolites was done by an in-house database using UHPLC-QTOF-MS. Fifty-seven metabolites were identified from the full scan of electrospray ionization positive and negative mode from the neem toddy extract by using UHPLC-QTOF-MS. Further confirmation of 31 of these metabolites was done by obtaining MS/MS spectrum from UHPLC-QTOF-MS. Principal component analysis study of metabolites from neem toddy with leaves, seed, seed coat, and bark revealed that they are closely related to those contained in neem seeds and seed coats. Azadirachtin, nimbidiol, 22,23dihydroazadirachtin, nimbonone, nimbonolone, nimosone, and 6-deacetylnimbinene were found to be some of the most abundant metabolites in neem toddy. The neem toddy extract showed significant anti-inflammatory activity when tested in N9 murine microglial cells with $25 \mathrm{ng}$ of recombinant mouse tumor necrosis factor alpha protein (active) using qRT-PCR. The active metabolites in neem toddy could be further explored for their therapeutic potentials.

\section{ABBREVIATIONS}

ESI electrospray ionization

RT retention time

PCA principal component analysis

TNF tumor necrosis factor 


\section{Introduction}

Neem (Azadirachta indica) belongs to the family Meliaceae and is commonly found in Asia and Africa. Neem leaves, fruits, seeds, bark, flowers, gum, oil, and cake are useful non-wood products [1]. These non-wood products have been reported to have anti-allergenic, antibacterial, antiviral, anti-inflammatory, antidiabetic, mosquito-repellent, larvicidal, spermicidal, and other biological activities [1]. Nimbin was first isolated by Siddiqui in 1942. Following this, more than 250 natural products have been identified from different parts of the neem tree. These include diterpenoids, triterpenoids, steroids, flavonoids, coumarins, hydrocarbons, fatty acids. Among these, the triterpenoids constitute a major group of compounds known to have insecticidal and a broad range of pharmaceutical activities [2-4]. From ancient times, different parts of the neem tree have been used as routine medicinal household remedies. Apart from its therapeutic applications, it has also been used as a commercial insecticide and agrochemical [5-7]. The aqueous extracts from various parts of neem and their active principles are known to exhibit antifungal activities and have been extensively studied by numerous researchers in the past $[8,9]$.

More than 150 tetranortriterpenoids [3] have been isolated and characterized from various parts of the neem tree. These compounds are highly oxygenated and have a very complex skeletal structure. Based on the skeletal alteration, these triterpenoids can be classified into two groups: ring-intact (basic) triterpenoids and C-seco triterpenoids $[3,10]$. Ring-intact triterpenoids contain a 4,4,8-trimethyl-17-furanylsteroidal skeleton, such as azadirone, azadiradione, and gedunin types of structures. On the other hand, C-seco triterpenoids are formed by the opening and further rearrangements of the $\mathrm{C}$-ring, thus producing nimbin, salannin, and azadirachtin types of skeletons [4].

Plants contain many chemical compounds, different from the intermediates and products of primary metabolism, which vary according to the family and species. The confined distribution of many such compounds called "secondary metabolites" can be used as taxonomic markers and are responsible for specific odors, tastes, and colors of plants [11]. Hence secondary metabolites can be considered as an intrinsic signature of that species [4]. LC-MS has become one of the most preferred platforms for metabolomics studies because of its high throughput, soft ionization, mass accuracy, and good coverage of metabolites [12]. LC-MS-based untargeted metabolomics is a very useful analytical method to identify and quantify both known and unknown metabolites [13]. UHPLC-QTOF is a powerful analytical technique in metabolomics because of its high sensitivity, mass accuracy, and resolution. It is one of the most preferred analytical techniques due to its ease of sample preparation and extended dynamic range of metabolites [4, 12, 14-16].

Neem exudate or toddy is a strong-smelling, milky white liquid secreted usually from the joints between 2 main branches of old trees. The reason and mechanism of this secretion are not known, nor the age at which it occurs. At first, the toddy is secreted quite fast, but gradually the flow slows down and finally stops. The secretion may continue for more than a month. Neem toddy is acidic and has a pH of 3.5-5.0. It contains 89.7-92.0\% water, amino acids, sugars, resin, phosphorus, and protein [8]. Neem toddy is used in traditional medicine. Because it is a potent blood purifier and has bactericidal and antifungal properties, it has been beneficial in long-standing cases of leprosy, gout, fever, venereal diseases, stomach ache, atonic dyspepsia, and general debility [9].

In the current study, metabolic profiling of neem toddy was done to identify the triterpenoid constituents using UHPLC coupled to QTOC-MS for possible therapeutic application. Using PCA, we tried to establish similarities between the neem toddy and other parts of the neem tree with respect to the presence of the tri- and tetraterpenoids.

\section{Results and Discussion}

The metabolites were identified by obtaining the exact mass measurement of the precursor ions. Then the mass measurements were assessed against the experimental and theoretical isotopic patterns employing the PCDL manager file. Twenty-nine metabolites were identified from the ESI positive mode. > Table 1 shows their experimental masses, mass error (ppm), and overall identification scores of the isotopic pattern (calculated according to the exact masses, relative abundances, and spacing). An overlay of the extracted ion chromatograms of precursor ions identified in neem toddy extracts in ESI positive mode is shown in — Fig. 1. Similarly, 28 metabolites were identified from the ESI negative mode. They are listed in $\triangleright$ Table $\mathbf{2}$.

Metabolites identified in the MS scan were further confirmed by performing MS/MS analysis. Metabolites were confirmed by comparing the MS scan RT against MS/MS retention time. The metabolite at a particular RT was confirmed from the fragmentation pattern of spectra. Loss of hydroxyl and acetate ions was found to be very common in limonoids and terpenoids. Neutral loss of water and acetic acid were also very prominent in the fragmentation pattern of the metabolites. Seventeen metabolites were confirmed from the MS/MS fragmentation pattern analysis of neem toddy extract in ESI positive mode, and 14 metabolites were confirmed in ESI negative mode.

Diepoxyazadiradione (peak 4), gedunin (peak 5), $1 \alpha-2 \alpha$ epoxynimbinin (peak 6), $1 \beta$-2 $\beta$-epoxynimbinin (peak 7), and nimbinin (peak 8) are 5 metabolites with the same molecular formula $\mathrm{C}_{28} \mathrm{H}_{34} \mathrm{O}_{7}$ and same molecular mass 482.2305 . We obtained a precursor ion, $\mathrm{m} / \mathrm{z} 483.2381$ at retention time 11.435 min with a $99.26 \%$ identification score in ESI positive mode. Hence, this peak has been identified as the $[\mathrm{M}+\mathrm{H}]^{+}$ion peak for all 5 isomeric compounds with molecular formula $\mathrm{C}_{28} \mathrm{H}_{34} \mathrm{O}_{7}$ and molecular mass of 482.2305 .

6-deacetylnimbinolide (peak 2) and 6-deacetylphotonimbin (peak 3) are 2 stereoisomers that elute at RT $11.202 \mathrm{~min}$. MS/MS fragments at $\mathrm{m} / \mathrm{z} 514.1051,457.1479$, and 413.1565 satisfy the structure of both metabolites, but it was impossible to differentiate between these 2 stereoisomers even after obtaining the MS/MS fragments.

Peak 17 of the chromatograms in $>$ Fig. 1 corresponds to azadirachtin L. It elutes out of the column at retention time 17.311 min. Azadirachtin $\mathrm{L}$ has a molecular formula $\mathrm{C}_{35} \mathrm{H}_{44} \mathrm{O}_{15}$ with a mass of 704.268. Its $[\mathrm{M}+\mathrm{H}]^{+}$ion was observed at $\mathrm{m} / \mathrm{z} 705.2664$ with an $\mathrm{m} / \mathrm{z}$ tolerance of $0.16 \mathrm{ppm}$ and an identification score of $98.69 \%$. The MS/MS spectrum of azadirachtin $L$ is represented in $>$ Fig. 15 of the Supplementary data.

Azadirachtin L is a C-seco terpenoid (i. e., opened and modified C-ring). \& Figure 2 represents the fragmentation pattern of the molecular ion of azadirachtin L in ESI negative mode. The MS/MS fragments at $\mathrm{m} / \mathrm{z} 687.2618$ are the base peak formed probably due 
- Table 1 Metabolites identified from UHPLC-QTOF-MS SCAN of neem toddy extract in ESI positive mode

\begin{tabular}{|c|c|c|c|c|c|c|c|c|}
\hline Peak & Name & $\mathrm{RT}(\min )$ & $\mathrm{m} / \mathbf{z}$ & $\begin{array}{l}\text { Precursor ion } \\
\text { form }\end{array}$ & $\begin{array}{l}\text { Formula } \\
\text { (Tgt) }\end{array}$ & $\begin{array}{l}\text { Mass } \\
\text { (Tgt) }\end{array}$ & $\begin{array}{l}\text { Diff } \\
\text { (Tgt, ppm) }\end{array}$ & Id Score, \% \\
\hline 1 & Margolonone & 10.003 & 337.1424 & {$[\mathrm{M}+\mathrm{Na}]^{+}$} & $\mathrm{C}_{19} \mathrm{H}_{22} \mathrm{O}_{4}$ & 314.1518 & 4.82 & 72.22 \\
\hline 2 & 6-Deacetylnimbinolide & 11.202 & 531.2214 & {$[\mathrm{M}+\mathrm{H}]^{+}$} & $\mathrm{C}_{28} \mathrm{H}_{34} \mathrm{O}_{10}$ & 530.2152 & -3.76 & 73.43 \\
\hline 3 & 6-Deacetylphotonimbin & 11.202 & 531.2214 & {$[\mathrm{M}+\mathrm{H}]^{+}$} & $\mathrm{C}_{28} \mathrm{H}_{34} \mathrm{O}_{10}$ & 530.2152 & -3.76 & 73.43 \\
\hline 4 & DiepoxyAzadiradione & 11.435 & 483.2381 & {$[\mathrm{M}+\mathrm{H}]^{+}$} & $\mathrm{C}_{28} \mathrm{H}_{34} \mathrm{O}_{7}$ & 482.2305 & 0.89 & 99.26 \\
\hline 5 & Gedunin & 11.435 & 483.2381 & {$[\mathrm{M}+\mathrm{H}]^{+}$} & $\mathrm{C}_{28} \mathrm{H}_{34} \mathrm{O}_{7}$ & 482.2305 & 0.89 & 99.26 \\
\hline 6 & $1 \alpha-2 \alpha-E p o x y n i m b i n i n$ & 11.435 & 483.2381 & {$[\mathrm{M}+\mathrm{H}]^{+}$} & $\mathrm{C}_{28} \mathrm{H}_{34} \mathrm{O}_{7}$ & 482.2305 & 0.89 & 99.26 \\
\hline 7 & $1 \beta$-2 $2 \beta$-Epoxynimbinin & 11.435 & 483.2381 & {$[\mathrm{M}+\mathrm{H}]^{+}$} & $\mathrm{C}_{28} \mathrm{H}_{34} \mathrm{O}_{7}$ & 482.2305 & 0.89 & 99.26 \\
\hline 8 & Nimbinene & 11.435 & 483.2381 & {$[\mathrm{M}+\mathrm{H}]^{+}$} & $\mathrm{C}_{28} \mathrm{H}_{34} \mathrm{O}_{7}$ & 482.2305 & 0.89 & 99.26 \\
\hline IS & Hydrocortisone & 12.484 & 363.2162 & {$[\mathrm{M}+\mathrm{H}]^{+}$} & $\mathrm{C}_{21} \mathrm{H}_{30} \mathrm{O}_{5}$ & 362.2093 & -1.47 & 98.49 \\
\hline 9 & Limbocidin & 13.133 & 627.2439 & {$\left[\mathrm{M}+\mathrm{H}-\mathrm{H}_{2} \mathrm{O}\right]^{+}$} & $\mathrm{C}_{33} \mathrm{H}_{40} \mathrm{O}_{13}$ & 644.2469 & -0.45 & 97.98 \\
\hline 10 & Azadirachtin $\mathrm{H}$ & 15.33 & 667.2381 & {$\left[\mathrm{M}+\mathrm{Na}-\mathrm{H}_{2} \mathrm{O}\right]^{+}$} & $\mathrm{C}_{33} \mathrm{H}_{42} \mathrm{O}_{14}$ & 662.2575 & 3.99 & 92.12 \\
\hline 11 & 1-Detigloylazadirachtin (Azadirachtin E) & 15.68 & 645.253 & {$\left[\mathrm{M}+\mathrm{Na}-\mathrm{H}_{2} \mathrm{O}\right]^{+}$} & $\mathrm{C}_{31} \mathrm{H}_{44} \mathrm{O}_{14}$ & 640.2731 & 1.89 & 71.67 \\
\hline 12 & Azadirachtin B & 15.696 & 697.2462 & {$[\mathrm{M}+\mathrm{Na}]^{+}$} & $\mathrm{C}_{34} \mathrm{H}_{42} \mathrm{O}_{14}$ & 674.2575 & -0.4 & 71.06 \\
\hline 13 & $\begin{array}{l}\text { 11-dehydroxy-11-oxo-azadirachtin- } \\
\text { 11-12-lactone (Azadirachtin K) }\end{array}$ & 16.163 & 671.2358 & {$\left[\mathrm{M}+\mathrm{H}-\mathrm{H}_{2} \mathrm{O}\right]^{+}$} & $\mathrm{C}_{34} \mathrm{H}_{40} \mathrm{O}_{15}$ & 688.2367 & 3.48 & 84.29 \\
\hline 14 & Margocilin 1 & 16.828 & 317.2104 & {$[\mathrm{M}+\mathrm{H}]^{+}$} & $\mathrm{C}_{20} \mathrm{H}_{28} \mathrm{O}_{3}$ & 316.2038 & -1.35 & 81.72 \\
\hline 15 & Margosone & 16.828 & 317.2104 & {$[\mathrm{M}+\mathrm{H}]^{+}$} & $\mathrm{C}_{20} \mathrm{H}_{28} \mathrm{O}_{3}$ & 316.2038 & -1.35 & 81.72 \\
\hline 16 & Nimolinin & 16.828 & 317.2104 & {$[\mathrm{M}+\mathrm{H}]^{+}$} & $\mathrm{C}_{20} \mathrm{H}_{28} \mathrm{O}_{3}$ & 316.2038 & -1.35 & 81.72 \\
\hline 17 & Azadirachtin L & 17.311 & 705.2749 & {$[\mathrm{M}+\mathrm{H}]^{+}$} & $\mathrm{C}_{35} \mathrm{H}_{44} \mathrm{O}_{15}$ & 704.268 & -0.16 & 98.69 \\
\hline 18 & Nimbidiol & 19.642 & 275.1645 & {$[\mathrm{M}+\mathrm{H}]^{+}$} & $\mathrm{C}_{17} \mathrm{H}_{22} \mathrm{O}_{3}$ & 274.1569 & 2.9 & 84.92 \\
\hline 19 & Methylnimbiol & 21.873 & 287.2007 & {$[\mathrm{M}+\mathrm{H}]^{+}$} & $\mathrm{C}_{19} \mathrm{H}_{26} \mathrm{O}_{2}$ & 286.1933 & -0.19 & 98.1 \\
\hline 20 & Nimbisonol & 21.889 & 271.1697 & {$\left[\mathrm{M}+\mathrm{H}-\mathrm{H}_{2} \mathrm{O}\right]^{+}$} & $\mathrm{C}_{18} \mathrm{H}_{24} \mathrm{O}_{3}$ & 288.1725 & 1.66 & 84.97 \\
\hline 21 & Azadironolide & 21.889 & 451.2491 & {$\left[\mathrm{M}+\mathrm{H}-\mathrm{H}_{2} \mathrm{O}\right]^{+}$} & $\mathrm{C}_{28} \mathrm{H}_{36} \mathrm{O}_{6}$ & 468.2512 & 1.5 & 72.52 \\
\hline 22 & Isoazadiradionolide & 21.889 & 451.2491 & {$\left[\mathrm{M}+\mathrm{H}-\mathrm{H}_{2} \mathrm{O}\right]^{+}$} & $\mathrm{C}_{28} \mathrm{H}_{36} \mathrm{O}_{6}$ & 468.2512 & 1.5 & 72.52 \\
\hline 23 & 14-15-epoxynimonol & 21.889 & 451.2491 & {$\left[\mathrm{M}+\mathrm{H}-\mathrm{H}_{2} \mathrm{O}\right]^{+}$} & $\mathrm{C}_{28} \mathrm{H}_{36} \mathrm{O}_{6}$ & 468.2512 & 1.5 & 72.52 \\
\hline 24 & 1-Detigloyl-1-isovaleroylazadirachtin & 22.222 & 717.2756 & {$[\mathrm{M}+\mathrm{Na}]^{+}$} & $\mathrm{C}_{34} \mathrm{H}_{46} \mathrm{O}_{15}$ & 694.2837 & 3.88 & 90.57 \\
\hline 25 & 6-acetylnimbandiol & 22.672 & 499.2331 & {$[\mathrm{M}+\mathrm{H}]^{+}$} & $\mathrm{C}_{28} \mathrm{H}_{36} \mathrm{O}_{8}$ & 498.2254 & 0.92 & 99.41 \\
\hline 26 & Isonimolicinolide & 25.368 & 563.2259 & {$[\mathrm{M}+\mathrm{Na}]^{+}$} & $\mathrm{C}_{30} \mathrm{H}_{36} \mathrm{O}_{9}$ & 540.2359 & 1.76 & 98.89 \\
\hline 27 & 2-3-dehydro-salannol & 26.45 & 597.3066 & {$[\mathrm{M}+\mathrm{H}]^{+}$} & $\mathrm{C}_{34} \mathrm{H}_{44} \mathrm{O}_{9}$ & 596.2985 & 1.31 & 98.82 \\
\hline 28 & Nimbonolone & 28.481 & 301.2166 & {$[\mathrm{M}+\mathrm{H}]^{+}$} & $\mathrm{C}_{20} \mathrm{H}_{28} \mathrm{O}_{2}$ & 300.2089 & 1.51 & 98.76 \\
\hline 29 & Nimbonone & 28.481 & 301.2166 & {$[\mathrm{M}+\mathrm{H}]^{+}$} & $\mathrm{C}_{20} \mathrm{H}_{28} \mathrm{O}_{2}$ & 300.2089 & 1.51 & 98.76 \\
\hline
\end{tabular}

to the loss of a water molecule from the carbon-7. Fragment ion at $\mathrm{m} / \mathrm{z} 627.2385$ is a moderately intense peak, which is an acetic acid loss at C-11; fragment ion at $\mathrm{m} / \mathrm{z} 567.1805$ is another acetic acid loss from $\mathrm{C}-3$. The daughter ion at $\mathrm{m} / \mathrm{z} 507.1557$ corresponds to a loss of a methyl formate molecule from C-4. These fragments confirmed the presence of azadirachtin $L$ in neem toddy.

Nimbidinin (peak 10), nimolicinoic acid (peak 11), and nimolicinolic acid (peak 12) are 3 isomers with molecular formula $\mathrm{C}_{26} \mathrm{H}_{34}$ $\mathrm{O}_{6}$ and molecular mass 442.2355 identified in ESI negative mode. These 3 isotopes eluted at RT $13.168 \mathrm{~min}$. MS/MS fragments at m/z 459.2360 correspond to the loss of the isopropyl radical from the precursor ion, and hence it eliminates nimbidinin because it does not have any isopropyl group. MS/MS fragment at m/z 430.9734 is a neutral loss of carbon monoxide. Hence, it confirms the presence of 2 stereoisomers, nimolicinoic acid and nimolicinolic acid.

Nimbinene is another C-seco triterpenoid that was found in the neem toddy. The probable mechanistic pathway for MS/MS fragments of nimbinene is represented in Scheme 1a and Scheme 1b in the Supplementary data. It describes the key fragmentation patterns observed in C-seco triterpenoids. The key fragment losses are water, acetic acid, tiglic acid, methanol, furan and carbon monoxide. Nimbinene showed a fragment at $\mathrm{m} / \mathrm{z} 483.2381[\mathrm{M}+\mathrm{H}]^{+}$. The fragment $[\mathrm{M}-\mathrm{MeOH}+\mathrm{H}]^{+}$is generated by removing methanol from the 11-methyl ester group as skeleton fragments. Other fragments are mainly obtained as fragmented skeleton along with the loss of one or more functional groups. Hence, these fragment ions are essential in characterizing the skeleton of C-seco triterpenoids and identifying the metabolite in unknown, complex phytochemical extracts.

To correlate between the metabolites in neem toddy and other parts of the neem tree, extracts from neem toddy, leaves, bark, seeds, and seed coats were analyzed in UPLC-QTOF triplicate. The peak area of each metabolite was normalized across all 5 samples. Statistical analysis was done using the online software MetaboAnalyst. The first 3 principal components explain $90 \%$ of variations across all 5 samples. A synchronized 3D PCA plot for all 5 samples is shown in > Fig. 3 for all 5 samples. PCA of metabolites across all the samples showed that metabolites of neem toddy were closely 


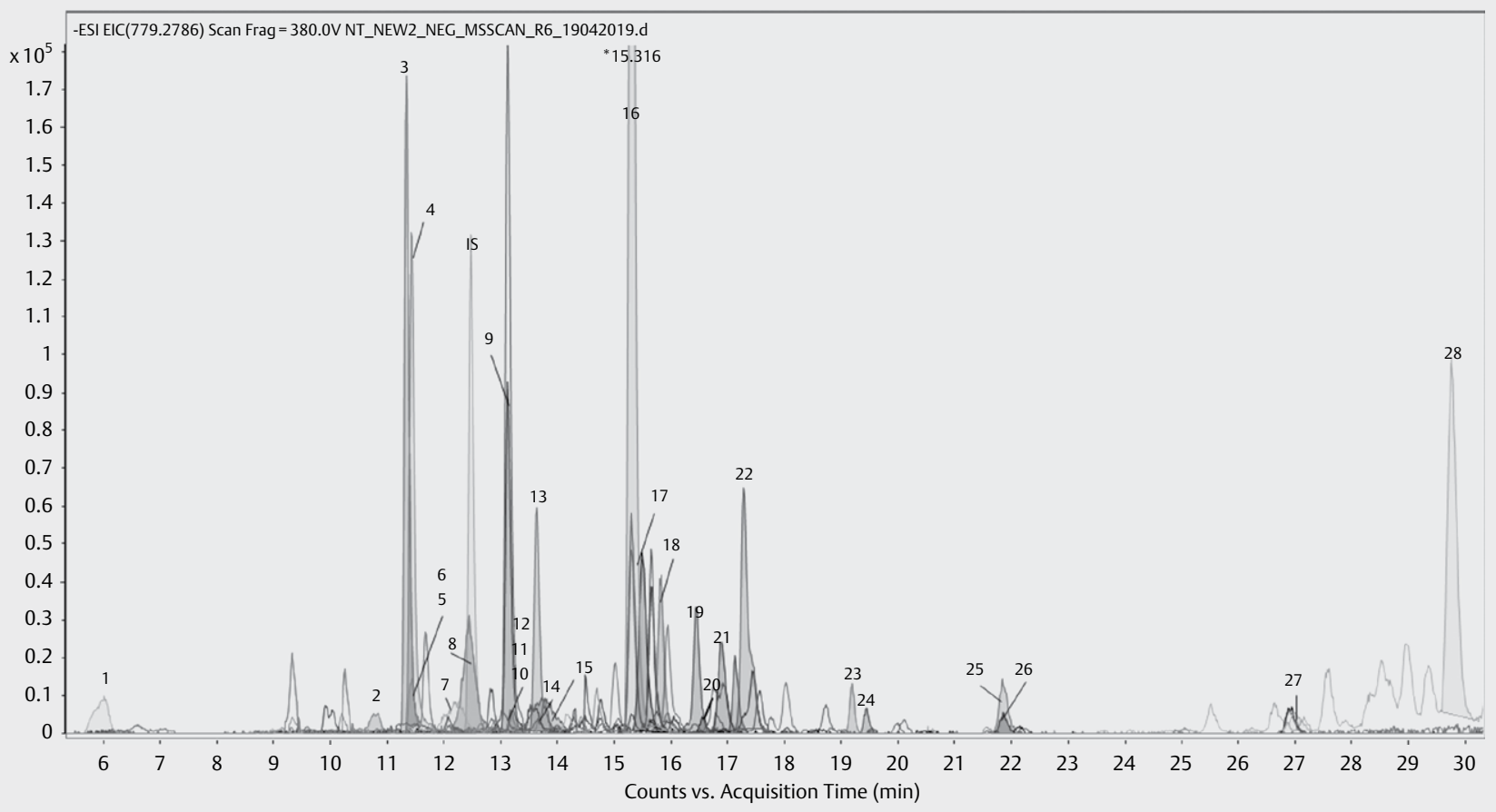

Fig. 1 Extracted ion chromatogram of precursor ions of metabolites present in neem toddy extract in ESI positive mode. The peak number corresponds to the metabolites in $>$ Table 1. IS, internal standard (Hydrocortisone).

related to metabolites from seed and seed coat extracts. Variation in metabolites of neem bark and leaves formed 2 separate clusters.

The heatmap is a commonly used visualization tool that provides intuitive insight into large metabolomic data sets [17]. Heatmap represents the relative abundance of metabolites identified from each sample by the intensity of color [18]. We performed hierarchical clustering on both variables (columns) and samples (rows) and generated a heatmap with dendrograms drawn on both sides. Patterns of metabolite concentration changes across all 5 samples were investigated, and the clusters were identified from the dendrograms. We used Euclidean for distance measures with the Ward clustering algorithm to generate a heatmap with hierarchical clustering. - Figure 4 shows the heatmap of all the 57 metabolites from all 5 samples. The heatmap with dendrograms supports the results from the PCA study that neem toddy is correlated with neem seed and seed coat.

Azadirachtin, nimbidiol, 22-23-dihydroazadirachtin, myristic acid, nimbonolone, nimbonone, 1-dihydrotigloyl-azadirachtin, scopoletin, nimbisonol, 3-O-deacetyl-azadirachtin, and azadirachtin $L$ were found to be the most abundant metabolites in neem toddy. These metabolites have been reported to have many therapeutic properties [19-22]. Azadirachtin and its derivative 22,23-dihydroazadirachtin were effective in preventing pupation and in causing larval mortality. Nimbonone, nimbonolone, and nimosone from neem bark extract can potentially develop novel medicines for the therapeutic control of gastric hyperacidity and ulcers [20]. Azadirachtin has also been reported to have neuroendocrine activity [21]. 6-deacetylnimbinene has been reported to have exhibited cytotoxicity against cancer cell lines with $\mathrm{IC}_{50}$ values in the range of
0.1-97.9 $\mu \mathrm{M}$ [22]. Figure 5 shows the expression of cytokine genes (TNF- $\alpha$, TGF- $\beta$, and IFN- $\gamma$ ) in control and treated samples at $6 \mathrm{~h}$. TNF- $\alpha$, TGF- $\beta$, and IFN- $y$ showed overexpression in the presence of TNF- $\alpha$ alone and showed reduced expression in the presence of the extract. The neem toddy extract showed better anti-inflammatory activity in case of TNF- $\alpha$ and TGF- $\beta$ compared to IFN- $\gamma$ at a concentration of $50 \mu \mathrm{g} / \mathrm{mL}$.

It has been shown that cytokine mRNA accumulation in the skin of leprosy patients is blocked by anti-inflammatory drugs that improve the clinical condition of reactional leprosy patients [23]. Neem toddy has been reported to be beneficial in long-standing cases of leprosy [9]. The activity of neem toddy against leprosy could be attributed to the anti-inflammatory activity of neem toddy extract shown in N9 murine cells treated with TNF- $\alpha$.

In conclusion, neem toddy could be an alternative for obtaining many bitter principles of neem such as nimbidiol, nimbonone, and nimbisonol, which are major metabolites present in neem toddy. The gene expression analysis using qPCR was performed using the delta-delta CT method and statistically analyzed using Student's t-Test.

\section{Materials and Methods}

\section{Chemicals and reagents}

Acetic acid was procured from Sigma-Aldrich Fulka. Hexane HPLC grade was purchased from Merck life science (Mumbai, India). Hydrocortisone analytical grade (internal standard, $\geq 98 \%$ ) was purchased from Sigma-Aldrich (Bangalore, India). Methanol, ace- 


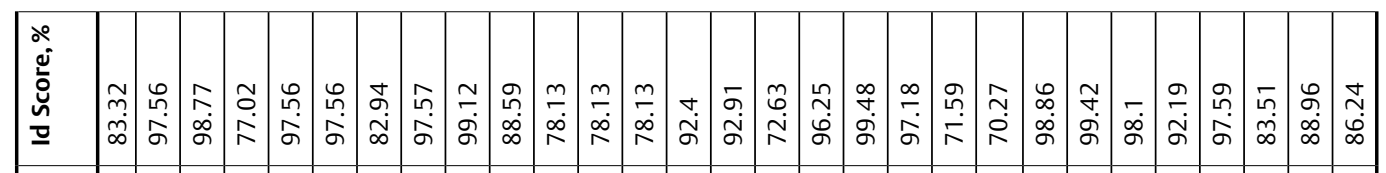

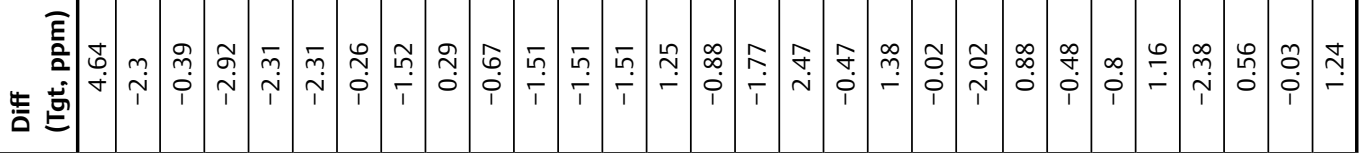

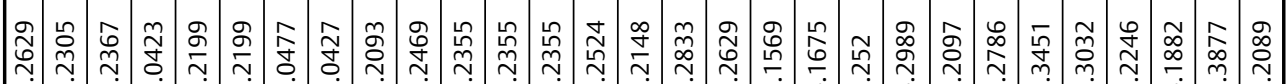

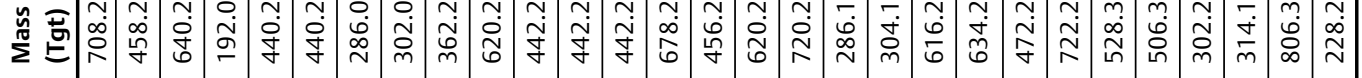

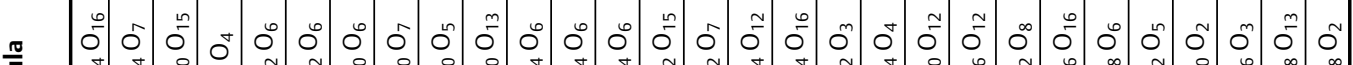

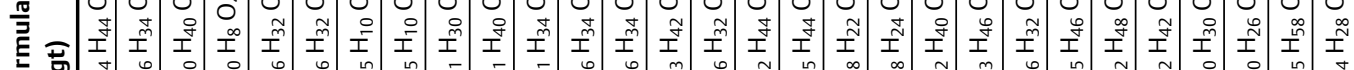

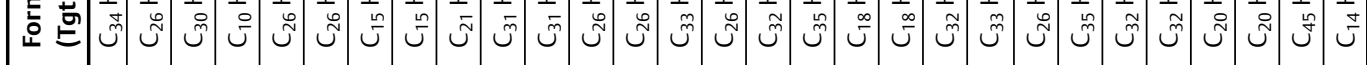

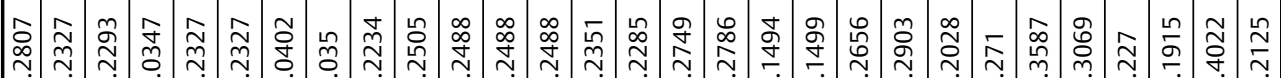

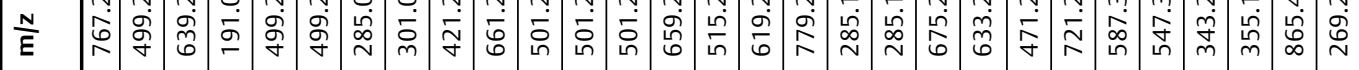

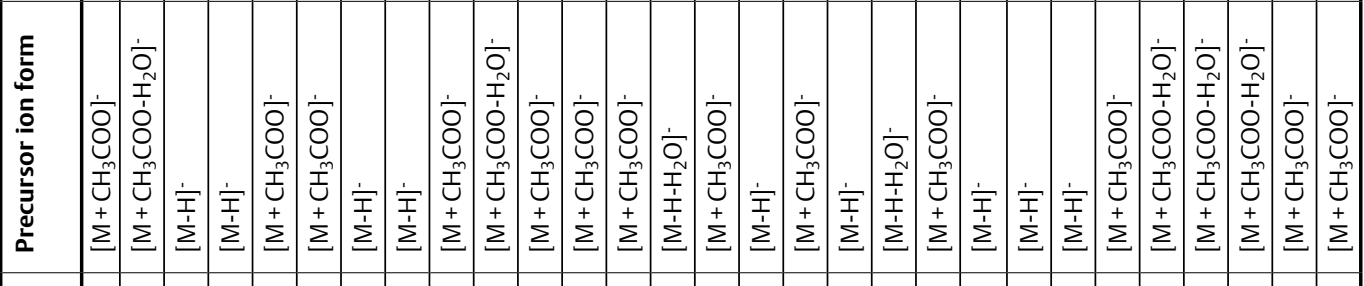

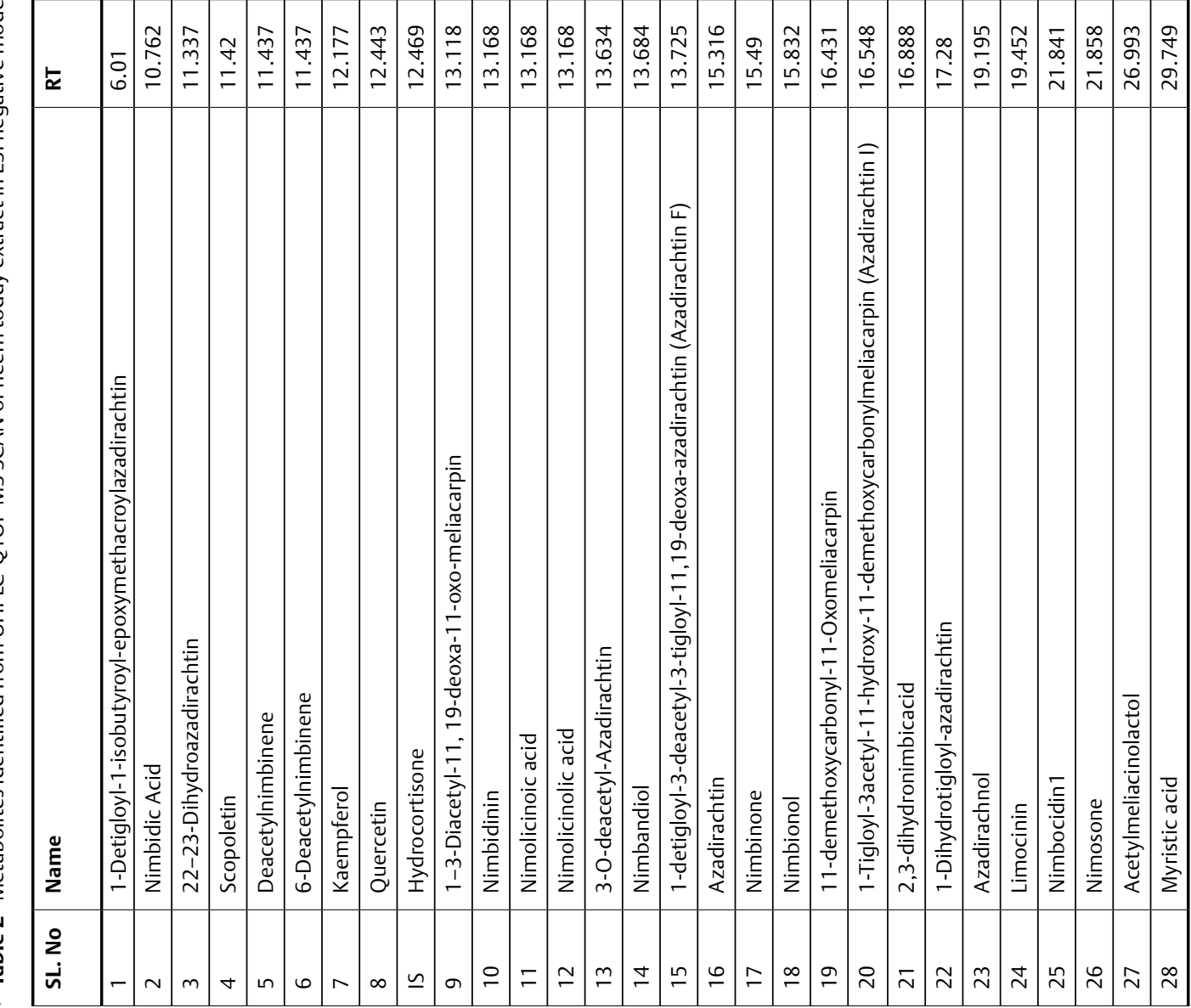




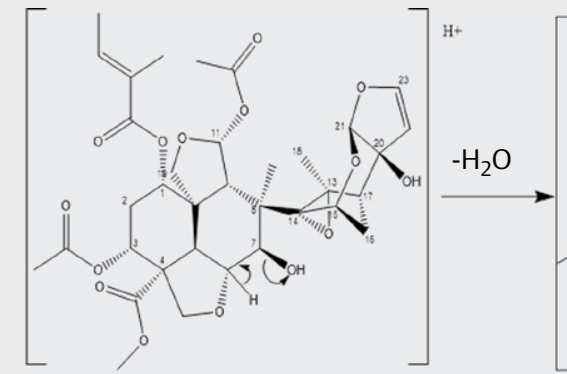

Azadirachtin L $\quad \mathrm{m} / \mathrm{z} 705.2749$

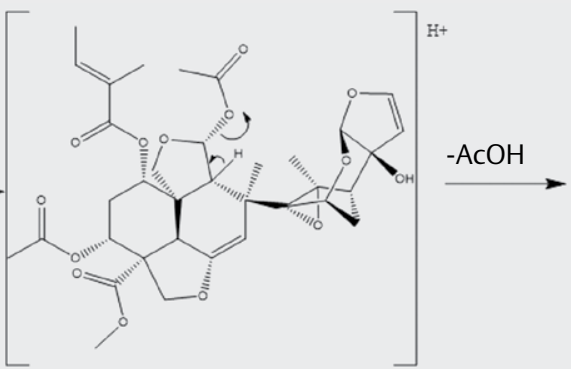

$\mathrm{m} / \mathrm{z} 687.2636$

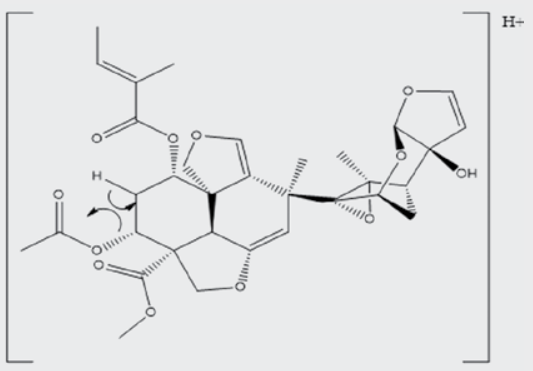

$\mathrm{m} / \mathrm{z} 627.2386 \quad-\mathrm{AcOH}$

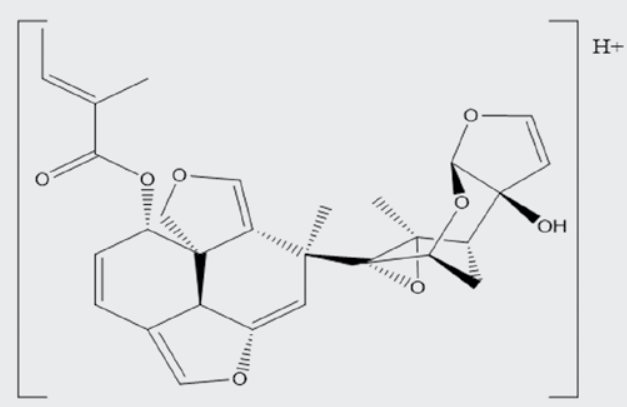

$\mathrm{m} / \mathrm{z} 507.157$
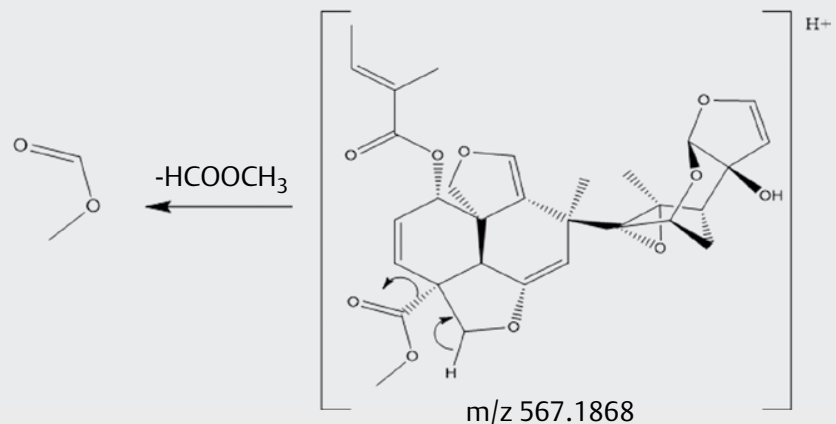

- Fig. 2 Mass fragmentation pattern of Azadirachtin L in ESI negative mode.

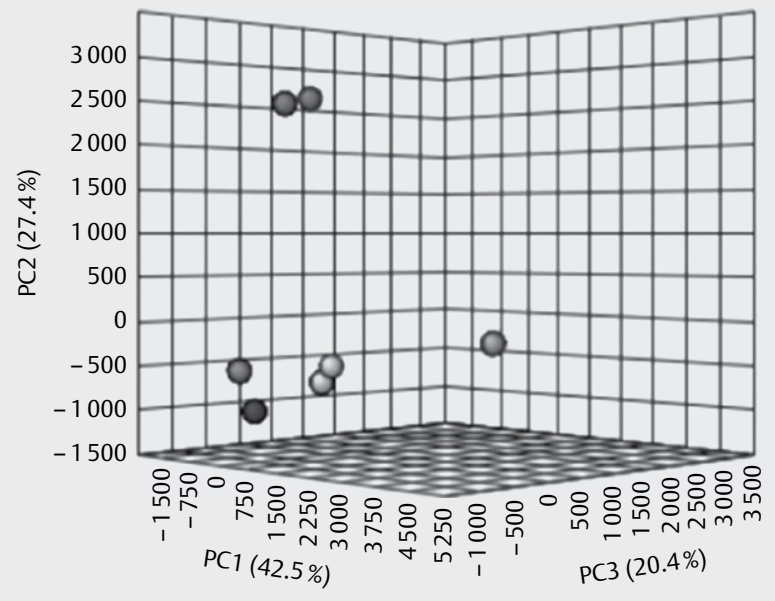

\begin{tabular}{|l|}
\hline \multicolumn{1}{|c|}{ Legend } \\
\hline NEEM_BARK \\
NEEM_LAEF \\
NEEM_SEED \\
NEEM_SEEDCOAT \\
NEEM_TODDY \\
\hline
\end{tabular}

Fig. 3 Synchronized 3D PCA plot of all 5 samples.

tonitrile, and water of LC/MS grade were procured from Fisher chemicals.

\section{Plant material}

Neem toddy was freshly collected in a bottle from a neem tree at Balangir, Odisha, India. The plant was identified and authenticated by botanist Prof. B. Ravi Prasad Rao from Sri Krishnadevaraya University (SKU), Anantapur, India. A voucher specimen was deposited at Sri Krishnadevaraya University Herbarium (SKU), Anantha- pur (registry number: Sri Satya Sai Institute of Higher Learning, Puttaparthi DRB \& PSK 57411[SKU]). Neem leaves, barks, and seeds were also collected from the same plant. Neem seed coats were separated manually from the seeds by peeling off the coats. Neem seeds, seed coats, barks, and leaves were then air-dried under shade at ambient temperature and pulverized using a laboratory grinder to obtain a coarse powder. These powders were stored at a dry place for further use until extraction. Neem toddy was also 


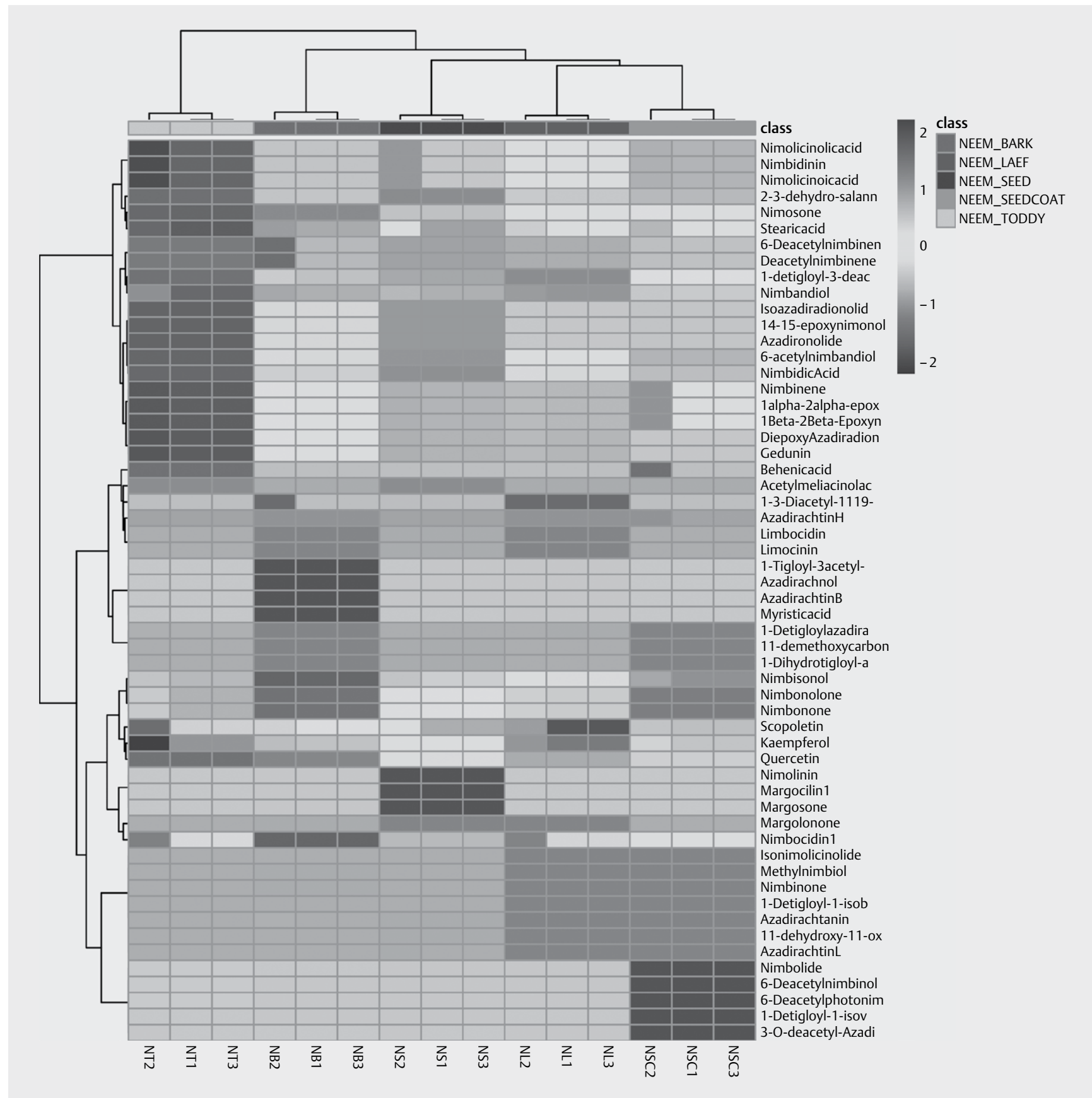

- Fig. 4 Heatmap of the metabolites; each row represents a metabolite, and column represents samples. Light grey represents more abundancy, and black represents less abundancy of metabolites. Shades of the color indicate the relative abundance.

immediately filtered to remove dust particles and stored at $-80^{\circ} \mathrm{C}$ until further use.

\section{Sample preparation}

Neem toddy was lyophilized to obtain a fine powder. Fifty mg of neem toddy powder was extracted by sonicating with $10 \mathrm{~mL}$ of LCMS grade methanol for $30 \mathrm{~min}$. The extract was then centrifuged, and the supernatant was filtered through PTFE $0.2 \mu \mathrm{m}$ filter. To $450 \mu \mathrm{L}$ of the neem toddy extract, $50 \mu \mathrm{L}$ of hydrocortisone $(1 \mu \mathrm{g} / \mathrm{mL})$ was added and vortexed to obtain a clear solution. The extract was transferred into a vial for LC-MS analysis.
The powders of the areal parts mentioned above were first defatted using $n$-hexane by refluxing for $6 \mathrm{~h}$. Five $\mathrm{g}$ each from the defatted powders of seeds, leaves, barks, and seed coats were further extracted with $150 \mathrm{~mL}$ of methanol for $6 \mathrm{~h}$ using Soxhlet apparatus. The methanol extract was then filtered and concentrated to 5-10 $\mathrm{mL}$ by using a rotary evaporator. These extracts were then transferred into sample bottles and purged with nitrogen to dryness. Five $\mathrm{mg}$ of each sample was reconstituted in $1 \mathrm{~mL}$ of LCMS grade methanol $(5000 \mu \mathrm{g} / \mathrm{mL})$ as a stock solution. Concentrations of extract were optimized for the proper separation of metabolites. 


\section{Anti-inflammatory activity of neem toddy}

Cell culture and treatment

N9 (microglial) cells were gifted by Dr. Anirban Basu, India. National Brain Research Centre Haryana cells were maintained in RPMI1640 (Gibco, Cat. No. 31800-089) medium supplemented with $10 \%$ FBS (Gibco, FBS, Qualified, Cat. No.10270106), 1 \% antibioticantimycotic (penicillin, streptomycin, amphotericin) solution (Invitrogen, Thermo Fisher Scientific Inc.) at $37^{\circ} \mathrm{C}$ in a humidified atmosphere with $5 \% \mathrm{CO}_{2}$. Cells were seeded at an appropriate density and treated either with $25 \mathrm{ng}$ of recombinant mouse TNF- $\alpha$ protein (active) (abcam Cat. No. ab9740, purity: $\geq 98 \%$ SDS-PAGE) or with $25 \mathrm{ng}$ of TNF- $\alpha$ in the presence of $50 \mu \mathrm{g} / \mathrm{mL}$ of neem toddy extract. Untreated cells were used as a control.

\section{RNA extraction and quantitative real-time polymerase chain reaction}

After $6 \mathrm{~h}$ of treatment of N9 cells with TNF- $\alpha(25 \mathrm{ng})$, total RNA was extracted using HiPur A total RNA Miniprep Purification kit (Himedia, Cat. No. MB 602). Subsequently, the mRNA was converted to cDNA using a cDNA synthesis kit following the manufacturer's instruction (Thermo Scientific, Verso cDNA Synthesis Kit). Briefly, $1 \mathrm{\mu g}$ of the purified total RNA was denatured by incubating at $25^{\circ} \mathrm{C}$ for $5 \mathrm{~min}, 46^{\circ} \mathrm{C}$ for $20 \mathrm{~min}$, and $95^{\circ} \mathrm{C}$ for $1 \mathrm{~min}$. Quantitative realtime polymerase chain reaction (RT-PCR) was performed in triplicates with the BIORAD SYBR Green qPCR Supermix using Quantstudio5 (Thermo Scientific). The chosen primers were designed with NCBI Primer Blast software and are listed below in $>$ Table 3. Expression was normalized to that of HMBS and HPRT. To determine the anti-inflammatory effects of neem toddy extract, the mRNA expression of TNF- $\alpha$, IFN- $\gamma$, and TGF- $\beta$ was done using qRT-PCR on murine microglial $\mathrm{N} 9$ cells.

Agilent UHPLC 1290 infinity binary pump coupled with Agilent 1290 Infinity Autosampler and Agilent 6550 iFunnel QTOF with dual jet stream ionization source was used as the analytical instrument. Each sample was analyzed in triplicate in full-scan acquisition mode. The ionization was done in both positive and negative modes. The data acquisition software used was Agilent MassHunter version B.05.00. The mobile phase used was $(A)$ water with $0.2 \% \mathrm{v} / \mathrm{v}$ acetic acid and (B) $100 \%$ acetonitrile. Zorbax RRHD Eclipse Plus C18 $(3.0 \times 100 \mathrm{~mm}, 1.8 \mu \mathrm{m})$ column was used as stationary phase for separation of metabolites. Gradient elution program was set as $5 \%$ to $40 \% \mathrm{~B}$ in $4 \mathrm{~min}, 40 \%$ to $60 \% \mathrm{~B}$ in next $12 \mathrm{~min}, 60 \%$ to $80 \% \mathrm{~B}$ in next $12 \mathrm{~min}, 80 \%$ to $95 \% \mathrm{~B}$ in $4 \mathrm{~min}$ and held at $95 \% \mathrm{~B}$ for $3 \mathrm{~min}$, and $95 \%$ to $5 \% \mathrm{~B}$ in next $3 \mathrm{~min}$ followed by a post time run of $2 \mathrm{~min}$ to equilibrate the column. Flow rate $0.200 \mathrm{~mL} / \mathrm{min}$; column temperature $25^{\circ} \mathrm{C}$.

Quadrupole time-of-flight conditions: sheath gas nitrogen 11 $\mathrm{L} / \mathrm{min}$ at $350^{\circ} \mathrm{C}$; drying gas nitrogen $11 \mathrm{~L} / \mathrm{min}$ at $250^{\circ} \mathrm{C}$; nebulizer pressure $35 \mathrm{psig}$, nozzle voltage $1500 \mathrm{~V}$, capillary voltage $3.5 \mathrm{kV}$. Signals were recorded in the range of $\mathrm{m} / \mathrm{z} 100$ to 1700 . Negative ion mass calibration was performed using standard mix G196985000 (Supelco, Inc.) and had a residual error for the expected masses between $\pm 0.2 \mathrm{ppm}$. Lock masses were TFA anion at $\mathrm{m} / \mathrm{z}$ 112.985587 and HP-0921 at m/z 1033.988109 (trifluoroacetic acid adduct). MS/MS conditions: the data were acquired using the extended dynamic range mode $(2 \mathrm{GHz})$. Four fixed collision energies, $10,20,30$, and $40 \mathrm{eV}$, were used to fragment precursor ions in the $\mathrm{m} / \mathrm{z} 100$ to 1700 range. The acquisition rate was 1 spectra/s.
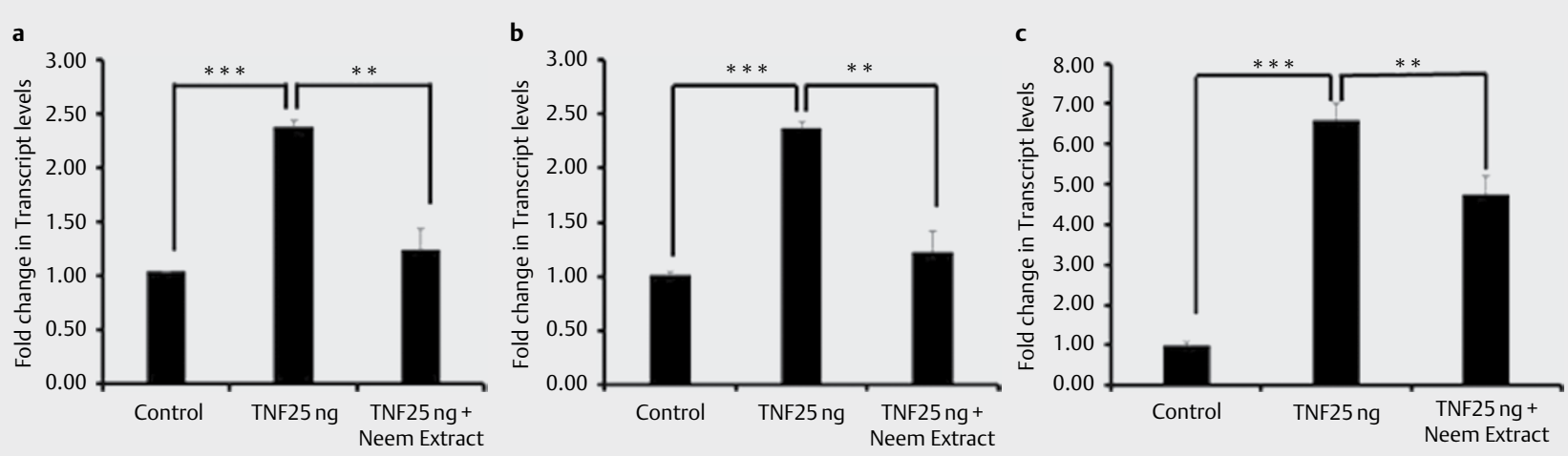

Fig. 5 Effect of inflammatory cytokines in N9 murine microglial cells treated with TNF $25 \mathrm{ng}$ alone and in combination with the neem toddy extract done using qRT-PCR at 6 hrs. a TNF- $\alpha$ expression; b TGF- $\beta$ expression; $\mathbf{c I F N}-\gamma$ expression. ${ }^{*} \mathrm{p} \leq 0.05 ;{ }^{* *} \mathrm{p} \leq 0.01 ;{ }^{* * *} \mathrm{p} \leq 0.001$. The significance was calculated using Student's t-test, and a p-value of $\leq 0.05$ was considered statistically significant.

- Table 3 Primer pair sets and parameters used in real time Polymerase chain reaction analysis

\begin{tabular}{|l|l|l|}
\hline Gene & Primer Sequence (5' $\mathbf{3}^{\prime}$ ') Forward & Primer Sequence (3'-5') Reverse \\
\hline TGF $\beta$ & GAACCAAGGAGACGGAATACAG & GGAGTTTGTTATCTTTGCTGTCAC \\
\hline TNF $\alpha$ & TCTTCTGTCTACTGAACTTCG & AAGATGATCTGAGTGTGAGGG \\
\hline IFNy & GAAAGACAATCAGGCCATCAG & GCATCCTTTTTCGCCTTGCT \\
\hline HPRT & AGGGATTTGAATCACGTTTG & TTTACTGGCAACATCAACAG \\
\hline HMBS & CCGAGCCAAGGACCAGGATA & CTCCTTCCAGGTGCCTCAGA \\
\hline
\end{tabular}




\section{Library searching}

Agilent Personal Compound Database and Library (PCDL) was used to generate the customized database containing 250 metabolites obtained from vmsrfdatabase.org. Agilent MassHunter Qualitative Analysis B.7.00 (MassHunter Qual, Agilent Technologies) was used for data processing. The database was uploaded to MassHunter and searched by using the option "find by formula." The PCDL search process integrates the chromatogram within a specified mass window and generates a match score based on the combination of accurate mass, isotopic abundance, and isotopic spacing of the identified compounds [24]. Confidence of compound identification is based on accurate mass and isotope pattern and was expressed by "overall identification score," Identification score is computed as a weighted average of the isotopic pattern signal of the compound. The identification score was more than $70 \%$, with a mass tolerance and mass error window of less than 5 ppm for all the identified compounds.

\section{Statistical analysis}

All the experimental data were obtained in triplicate for statistical analysis. The area of all the metabolites in all 5 samples was normalized with the area of internal standard (Hydrocortisone). MetaboAnalyst, an online software, was used for statistical analysis. The first 3 principal components were used to generate the synchronized 3D PCA plot. The gene expression analysis using qPCR was performed using the delta-delta CT method and statistically analyzed using Student's t-test.

\section{Acknowledgments}

For his constant inspiration, the authors are grateful to Bhagawan Sri Sathya Sai Baba, Founder Chancellor of Sri Sathya Sai Institute of Higher Learning. The authors are thankful to CRIF, SSSIHL for providing the necessary facilities.

\section{Conflicts of Interest}

The authors declare that they have no conflicts of interest.

\section{References}

[1] Kumawat KR, Kumar R. Pharmacological and therapeutical overview of neem (Azadirachta indica): A nature's drugstore. Int J Chem Sci 2018; 2: $23-27$

[2] Champagne DE, Koul O, Isman MB, Scudder GGE, Neil Tower GH. Biological activity of limonoids from the rutales. Phytochemistry 1992; 31: $377-394$

[3] Tan Q-G, Luo X-D. Meliaceous limonoids: chemistry and biological activities. Chem Rev 2011; 111: 7437-7522

[4] Pandreka A, Dandekar DS, Haldar S, Uttara V, Vijayshree SG, Mulani FA, Aarthy T, Thulasiram HV. Triterpenoid profiling and functional characterization of the initial genes involved in isoprenoid biosynthesis in neem (Azadirachta indica). BMC Plant Biol 2015; 15: 1-14

[5] Jacobson M. Focus on Phytochemical Insecticides: The Neem Tree. Boca Raton: CRC Press; 1988
[6] Morgan ED. Azadirachtin, a scientific gold mine. Bioorganic Med Chem 2009; 17: 4096-4105

[7] Elakovich SD. The neem tree: source of unique natural products for integrated pest management, medicinal, industrial, \& other purposes. J Am Chem Soc 2002; 118: 3999-4000. ISBN 3-527-30054-6

[8] Singh UP, Maurya S, Singh A, Singh M. Antifungal activity of neem (Azardirachta indica) toddy. Arch Phytopathol Plant Prot 2010; 43: 133-139

[9] Awantika J, Mridul R, Mishra HS, Lal JM, Nath YK. Nimba neera-The gift of nature. SAJP 2015; 4: 48-50

[10] Haldar S, Mulani FA, Aarthy T, Dandekar DS, Thulasiram HV. Expedient preparative isolation and tandem mass spectrometric characterization of C-seco triterpenoids from Neem oil. J Chromatogr A 2014; 1366: $1-14$

[11] Bennett RN, Wallsgrove RM, Bennett N, Wallsgrove M. Tansley Secondary Review No. 72. Metabolites in plant defence mechanisms. New Phytol 1994; 127: 617-633

[12] Zhou B, Xiao JF, Tuli L, Ressom HW. LC-MS-based metabolomics. Mol BioSyst 2012; 8: 470-481

[13] Vinayavekhin N, Saghatelian A. Untargeted metabolomics. Cur Protoc Mol Biol. 2010; Chapter 30: Unit 30.1 1-24

[14] Farag MA, Mohsen M, Heinke R, Wessjohann LA. Metabolomic fingerprints of 21 date palm fruit varieties from Egypt using UPLC/ PDA/ESI-qTOF-MS and GC-MS analyzed by chemometrics. Food Res Int 2014; 64: 218-226

[15] Hsu PC, Zhou B, Zhao Y, Ressom HW, Cheema AK, Pickworth W, Shields PG. Feasibility of identifying the tobacco-related global metabolome in blood by UPLC-QTOF-MS.. J Proteome Res 2013; 12: 679-691

[16] Jandrić Z, Roberts D, Rathor MN, Abrahim A, Islam M, Cannavan A. Assessment of fruit juice authenticity using UPLC-QToF MS: A metabolomics approach. Food Chem 2014; 148: 7-17

[17] Xia J, Wishart DS. Metabolomic data processing, analysis, and interpretation using metaboanalyst. Curr Protoc in Bioinformatics. 2011; 14.10.1-14.10.48

[18] Benton PH, Ivanisevic J, Rinehart D, Epstein A, Kurczy ME, Boska MD, Gendelman H, Siuzdak G. An interactive cluster heat map to visualize and explore multidimensional metabolomic data. Metabolomics 2015; 11: $1029-1034$

[19] Mukherjee A, Sengupta S. Characterization of nimbidiol as a potent intestinal disaccharidase and glucoamylase inhibitor present in Azadirachta indica (neem) useful for the treatment of diabetes. J Enzyme Inhib Med Chem 2013; 28: 900-910

[20] Maity P, Biswas K, Chattopadhyay I, Banerjee RK, Bandyopadhyay U. The use of neem for controlling gastric hyperacidity and ulcer. Phyther Res 2009; 23: 747-755

[21] Subrahmanyam B, Rembold H. Effect of azadirachtin A on neuroendocrine activity in Locusta migratoria. Cell Tissue Res 1989; 256: 513-517

[22] Takagi M, Tachi Y, Zhang J, Shinozaki T, Ishii K.Kikuchi Ukiya M, Banno $\mathrm{N}$, Tokuda H, Akihisa T. Cytotoxic and melanogenesis-inhibitory activities of limonoids from the leaves of Azadirachta indica (Neem). Chem Biodivers 2014; 11: 451-468

[23] Moraes MO, Sarno EN, Teles RMB, Almeida AS, Saraiva BCC, Nery AAC, Sampaio EP. Anti-inflammatory drugs block cytokine mRNA accumulation in the skin and improve the clinical condition of reactional leprosy patients. J Invest Dermatol 2000; 935-941

[24] Zhu Z-J, Schultz AW, Wang J, Johnson CH, Yannone SM, Patti G], Siuzdak G. Liquid chromatography quadrupole time-of-flight mass spectrometry characterization of metabolites guided by the METLIN database. Nat Protoc 2013; 8: 451 